\title{
ANALISA KERUSAKAN JALAN BETON PADA RUAS JALAN DESA BADURAME-GEGER KECAMATAN TURI
}

\author{
Hardi Susilo1, Sugeng Dwi Hartantyo² \\ ${ }^{1}$ Program Studi Teknik Sipil Fakultas Teknik Universitas Islam Lamongan, \\ ${ }^{2}$ Fakultas Teknik Program Studi Teknik Sipil Univesitas Islam Lamongan, \\ email: hardisusilo40@gmail.com,sugeng.dwih@gmail.com
}

\begin{abstract}
Badurame Village Street-Geger is a very important means of transportation. This is to support the economy of rural communities. The street is built by self-management way that has $3 \mathrm{~m}$ wide and $2500 m$ long. Badurame Village Street-Geger is an area that connects one settlement with the other settlements and one of the main accesses to the main road. Given the importance of transportation, the researcher conducted a research to determine the damage that occurred on the street. This study uses Bina Marga method, this method is used as a reference in the implementation, planning and solutions to the damage. From these results, the cause of the road damage on Badurame Village Street-Geger is the lack of reinforcement on the plate, aiming to minimize the lengthwise cracks because cracks is the most dominant reached $9.33 \%$ and reduced quality of concrete due to the lack of supervision. Amount of damage on the Badurame Village Street-Geger is the rift that extends reached $9.33 \%$. Waning concrete is $0.08 \%$, collapsed road is $0,093 \%$ and cracks crosways is $0.2 \%$. Solutions to overcome damage on the Badurame Village Street-Geger using method or reference from Bina Marga is patching, resurfacing, filling, local reconstruction and overlay.
\end{abstract}

Keywords: Concrete Damage Road, Waning Concrete, Cracks Crossway, Longitudinal Cracks, Collapsed Road

\section{PENDAHULUAN}

Perkerasan jalan merupakan lapisan perkerasan yang terletak diantara lapisan tanah dasar dan roda kendaraan yang berfungsi memberikan pelayanan kepada sarana transportasi dimana diharapkan selama masa pelayanan tidak terjadi kerusakan yang berarti.Agar tercipta jalan yang aman, nyaman dan memberikan manfaat yang signifikan bagi kesinambungan dan keberlangsungan hidup masyarakat luas dan menjadi salah satu faktor menjadikannya peningkatan kehidupan masyarakat dari beberapa aspek - aspek kehidupan.Jika perkerasan jalan dalam kondisi baik maka arus lalu lintas akan berjalan dengan lancar, demikian sebaliknya kalau perkerasan jalan rusak, lalu lintas akan sangat terganggu. Secara umum ada dua jenis konstruksi perkerasan jalan yaitu perkerasan lentur (flexible pavement) dan perkerasan kaku (rigid pavement).Perkerasan kaku (rigid pavement) terdiri dari pelat beton, lapis pondasi dan tanah dasar.Kebijakan untuk memperkecil pelanggaran muatan berlebih dengan tujuan agar konstruksi jalan relatif sesuai dengan umur rencana (masa layanan), dengan biaya pemeliharaan sesuai rencana, dapat dilakukan dengan cara mengefisienkan dana yang digunakanuntuk pelaksanaan perubahan konstruksi perkerasan jalan atau perubahan sumbu kendaraan.Berdasarkan pengikatnya perkerasan kaku (rigid pavment) adalah suatu susunan konstruksi perkerasan dimana sebagai lapisan atas digunakan plat beton yang terletak diatas pondasi atau langsung diatas tanah dasar pondasi (sub grade). Tujuan penelitian ini adalah untuk mengetahui penyebab kerusakan Jalan 
Penghubung ke Desa Badurame-Geger dan solusi mengantisipasi masalah tersebut.

\section{METODE PENELITIAN}

Penelitian ini menggunakan metode pengamatan dan mendokumentasikan langsung dilapangan untuk mengambil sampel permasalahan yang ada di lapangan. Lokasi Penelitian berada pada Jalan Desa Badurame-Geger Kecamatan Turi Kabupaten Lamongan. Data - data yang diperlukan pada tugas akhir terbagi menjadi dua, yaitu sebagai berikut :

1.Data primer

2.Data sekunder

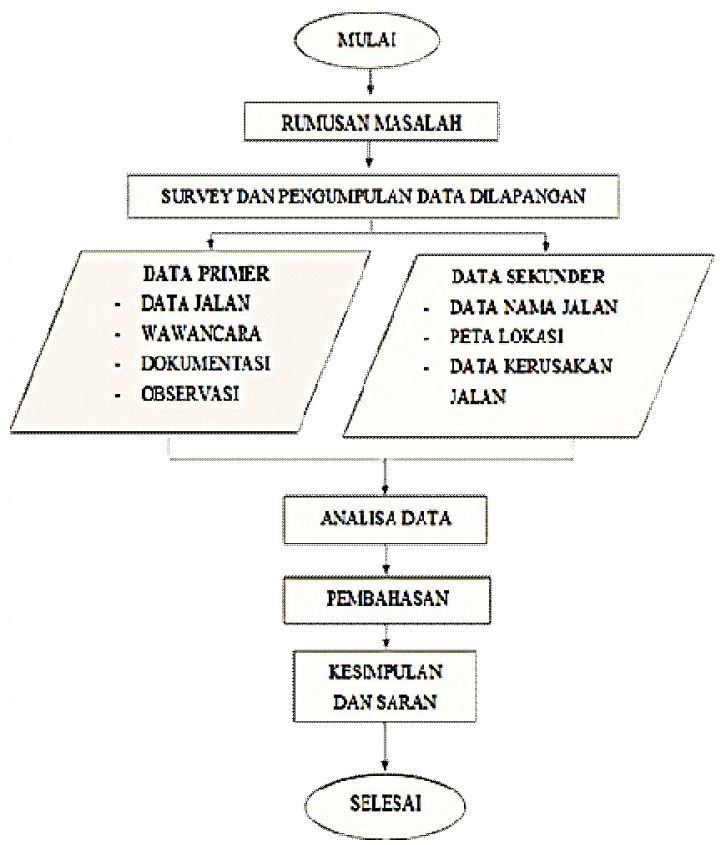

Gambar 2.Flow Chart Diagram Alur Penelitian

\section{HASIL DAN PEMBAHASAN}

Pada proyek pekerjaan jalan Desa Badurame-Geger sistem pengerjaannya dilakukan dengan caraswakelola. Hal ini untuk meminimalisir anggaran yang dibantu oleh pemerintah dan dana dari swadaya masyarakat setempat untuk menambah kekurangan-kekurangan baik dari segi material maupun kekurangan-kekurangan lainnya. Dalam pelaksanaan masyarakat setempatmengerjakan dan mengelolahnya sendiri baik dari segi manajemen dan pelaksanaannya. Untuk seluruh warga, dibagi untuk setiap RT melakukan satu bagian unit kerja. Untuk setiap unit kerja diberi tugas untuk membuat satu campuran beton dalam molen dan pelaksanaan dibantu oleh pihakpihak dari perangkat desa sebagai pengawas dan pelaksana. Proyek jalan Desa BadurameGeger dikerjakan pada tahun 2010, sehingga umur jalan sampai dengan saat ini sudah berumur 6 tahun.

\section{Tabel 1. Pengamatan Jalan}

\begin{tabular}{llllllll}
\hline \multirow{2}{*}{$\begin{array}{c}\text { Nama } \\
\text { jalan }\end{array}$} & \multirow{2}{*}{$\begin{array}{c}\text { Lebar } \\
(\mathrm{m})\end{array}$} & $\begin{array}{c}\text { Panjang } \\
(\mathrm{m})\end{array}$ & \begin{tabular}{c} 
Kelas \\
\cline { 5 - 6 }
\end{tabular} & Jalan & Jalur & Lajur & $\begin{array}{c}\text { Jenis } \\
\text { perkerasan }\end{array}$ \\
\hline $\begin{array}{c}\text { Badurame } \\
\text {-Geger }\end{array}$ & 3 & 2500 & IIIC & 2 & 2 & Rigid \\
\hline \multicolumn{3}{c}{ Sumber:Hasil pengamatan } & & & &
\end{tabular}

Setelah dilakukan pengamatan lapangan maka didapatkan data kerusakan jalan, sebagai berikut:

Tabel 2. Data Kerusakan jalan (Nr)

\begin{tabular}{cccc}
\hline No & $\begin{array}{c}\text { Jenis kerusakan } \\
\text { jalan }\end{array}$ & $\begin{array}{c}\text { Luaskerusakan } \\
\text { jalan }\left(\mathrm{m}^{2}\right)\end{array}$ & $\begin{array}{c}\text { Luas jalan } \\
\left(\mathrm{m}^{2}\right)\end{array}$ \\
\hline 1 & Memudarnya beton & 6 & 7500 \\
2 & Retak memanjang & 700 & 7500 \\
3 & Amblas & 7 & 7500 \\
4 & Retak Melintang & 15 & 7500 \\
\hline \multicolumn{3}{c}{ Sumber:Hasil Perhitungan }
\end{tabular}

Dari berbagai jenis kerusakan jalan dapat dicari besar nilai kerusakannya.Nilai kerusakan (Nr) diperoleh dari jumlah keseluruhan dan nilai kerusakan per setiap jenis kerusakan (Nq).Untuk Penilaian kondisi permukaandicari nilai prosentase kerusakan $(\mathrm{Np})$.

Tabel 3. Prosentase Kerusakan (Np)

\begin{tabular}{ccc}
\hline No & Jenis kerusakan & $\begin{array}{c}\text { Prosentase } \\
\text { kerusakan }\end{array}$ \\
\hline 1 & Memudarnya beton & $0,08 \%$ \\
2 & Retak memanjang & $9,33 \%$ \\
3 & Amblas & $0,093 \%$ \\
4 & Retak Melintang & $0,2 \%$ \\
\hline \multicolumn{2}{c}{ Sumber:Hasil perhitungan }
\end{tabular}


Tabel 4. Nilai Prosentase Kerusakan Jalan

\begin{tabular}{ccc}
\hline Prosentase & Kategori & Nilai \\
\hline$<5 \%$ & Sedikit sekali & 2 \\
$5 \%-20 \%$ & Sedikit & 3 \\
$20-40 \%$ & Sedang & 5 \\
$>40 \%$ & Banyak & 7
\end{tabular}

Sumber:Bina Marga

Setelah nilai $(\mathrm{Np})$ diperoleh selanjutnya dihitung nilai kerusakan $(\mathrm{Nq})$.

Tabel 5. Nilai bobot kerusakan

\begin{tabular}{cc}
\hline Jenis Kerusakan & Nilai \\
\hline Konstruksi beton tanpa kerusakan & 2 \\
Konstruksi penetrasi tanpa kerusakan & 3 \\
Tambalan & 4 \\
Retak & 5 \\
Lepas & 5,5 \\
Lubang & 6 \\
Alur & 6 \\
Gelombang & 6,6 \\
Amblas & 7 \\
Belahan & 7 \\
\hline
\end{tabular}

Sumber:Bina Marga

Tabel 6. Nilai Jumlah Kerusakan (Nq)

\begin{tabular}{|c|c|c|c|c|}
\hline \multirow[b]{2}{*}{ Jenis kerusakan } & \multicolumn{4}{|c|}{ Prosentase luar area kerusakan } \\
\hline & $\begin{array}{c}\text { Sedikit } \\
\text { sekali } \\
<5 \% \\
\end{array}$ & $\begin{array}{l}\text { Sedikit } \\
5 \%- \\
20 \% \\
\end{array}$ & $\begin{array}{c}\text { Sedang } \\
20- \\
40 \% \\
\end{array}$ & $\begin{array}{c}\text { Banyak } \\
>40 \%\end{array}$ \\
\hline Memudarnya beton & 11 & & 0 & 0 \\
\hline Retak memanjang & 0 & 15 & 0 & 0 \\
\hline Amblas & 14 & & 0 & 0 \\
\hline Retak melintang & 10 & & 0 & 0 \\
\hline
\end{tabular}

Sumber:Hasil pengamatan

Tabel 7. Nilai Kerusakan (Nr) Pada jalan Badurame-Geger

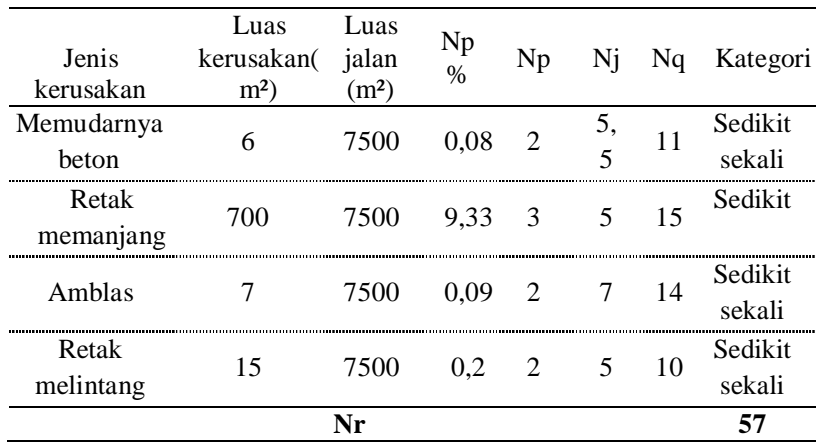

Sumber:Hasil Analisis

\section{Penyebab Kerusakan Jalan}

Analisa ini mencakup secara luas atau secara umum penyebab- penyebab kerusakan yang terjadi pada jalan,ada beberapa faktor penyebab kerusakan jalan.Berdasarkan penelitian, kendaraan yang lewat hanya didominasi roda dua dan kendaraan ringan saja.

\section{Material konstruksi perkerasan}

Makin banyak kesalahan dalam pemilihan dan perencanaan material konstruksi maka makin mempercepat kerusakan jalan.Penyebab kerusakan ini adalah kurangnya pengawasan dan proses pencampuran dari beton itu sendiri yang tidak sesuai prosedur karena sistem kerja bakti. Berdasarkan informasi proses pengadukan menggunakan mesin molen, campuran beton memakai ukuran timba cat yang ukuran $20 \mathrm{~kg}$. Untuk semen 1 sak menggunakan agregat kasar 6 timba dan agregat halus 7 timba.Tetapi dalam pelaksanaan takaran tersebut tidak digunakan. Selain itu,warga yang ikut kerja bakti tidak hanya laki-laki, warga perempuan juga dilibatkan karena adanya sistem denda. Sehingga dalam pelaksanaan, pengawasan harus lebih diperhatikan.

\section{Kondisi tanah dasar yang tidak stabil}

Kemungkinan kerusakan bisa juga diakibatkan turunnya tanah dasar karena disepanjang jalan dilalui sungai aliran irigasi.Selain itu faktor lapis pondasi bawah yang kurang kuat atau tidak rata, sehingga perlu dibangun dinding penahan atau disebut juga plengsengan.

\section{Tidak adanya tulangan}

Menurut Hendarsin (2007) Tujuan dasar distribusi penulangan baja adalah bukan untuk mencegah terjadinya retak pada plat beton tetapi untuk membatasi lebar retakan yang timbul pada daerah dimana beban terkonsentrasi agar tidak terjadi pembelahan plat beton pada daerah retak tersebut, sehingga kekuatan plat tetap dapat dipertahankan. Adapun dalam penelitian ini kerusakan terbesar adalah $700 \mathrm{~m}^{2}$ yaitu kerusakan retak memanjang. 
Kerusakan yang timbul tidak disebabkan oleh satu faktor saja, tetapi merupakan gabungan penyebab yang saling mengait.Berdasarkan dataproyek kegiatan yang dikerjakan adalah jalan rabat beton atau disebut pekerasan kaku (rigid pavment). Hal ini campuran yang digunakan adalah semen,agregat dan air sebagai bahan utama. Besi tulangan yang dipakai pada perkerasan kaku mempunyai fungsi sebagai berikut:

1. Membatasi lebar retakan agar kekuatan plat dapat dipertahankan

2. .Memungkinkan penggunaan plat yang lebih panjang agar dapat mengurangi jumlah sambungan melintang sehingga dapat meningkatkan kenyamanan

3. Mengurangi pengaruh kembang susut karena pengaruh perubahan suhu.

4. Mengurangi biaya pemeliharaan

Besi tulangan yang dipakai harus bersih dari oli, kotoran karat dan pengelupasan (Arthur Wignal, Peter S.Kendrick, Roy Ancil, Malcolm Copson .2003). Adapun karakteristik dari tulangan pelat pada perkerasan beton semen adalah sebagai berikut :

a. Bentuk tulangan pada umumnya berupa lembaran atau gulungan.

b. Fungsi dari tulangan beton ini yaitu untuk "memegang beton" agar tidak retak (retak beton tidak terbuka).

\section{Solusi Kerusakan dan Tindakan}

Adapun solusi kerusakan dan metode perawatan dan perbaikan Menurut bina marga No.10/BNKT/(1991).

Tabel 8. Klasifikasi Kerusakan dan Metode Perawatan dan Perbaikan

\begin{tabular}{|c|c|}
\hline Klasifikasi & Metode Perawatan dan Perbaikan \\
\hline $\begin{array}{l}\text { Memudarnya } \\
\text { beton }\end{array}$ & $\begin{array}{c}\text { Penambalan,perawatan } \\
\text { permukaan,pelapisan ulang }\end{array}$ \\
\hline $\begin{array}{c}\text { Retak } \\
\text { Memanjang }\end{array}$ & $\begin{array}{l}\text { Pengisian,rekonstruksi,penambalan,p } \\
\text { elapisan ulang }\end{array}$ \\
\hline Amblas & Rekonstruksi lokal,overlay \\
\hline $\begin{array}{l}\text { Retak } \\
\text { melintang }\end{array}$ & $\begin{array}{c}\text { Injeksi,penambalan,rekonstruksi,over } \\
\text { lay }\end{array}$ \\
\hline
\end{tabular}

Cara perawatan

Adapun cara perawatan antara lain:
1. Injeksi Material Penutup (sealant)

Yaitu dengan lebar kurang dari 0,5 $\mathrm{mm}$, retak yang berkembang seharusnya ditambal dengan campuran perekat sambungan sesudah membuat aluran sepanjang retak. Dimana penerusan beban tidak dapat dilakukan pada daerah retak.

2. Penambalan

Penambalan dilakukan dengan cara mengisi sambungan atau penggunaan metoda injeksi material penutup.Pada sambungandan retak-retak yang disebabkan oleh lepasnya material penutup atau material tersebut sudah seharusnya diganti. Apabilapada injeksi material penutupberlebihan yang mengakibatkan tidak ratanya permukaan jalan maka material tersebut harus diratakan sedemikian rupa sehingga tidak terlepas akibat lintasan kendaraan. Beberapa hal yang perlu diperhatikan dalam pelaksanaan pekerjaan injeksi material:

a. Bersihkan alur sambungan dan buanglah sisa-sisa material penutup dan material yang lain. Apabila material penutup masih berfungsi dengan baik maka material tersebut tidak perlu dibuang.

b. Sapu, sikat kawat, pahat, kompresor dan pembersih sambungan, dapat dipergunakan untuk membersihkan sambungan.

c. Sambungan harus dikeringkan sebelum diisi guna menjamin lekatan yang baik dari material pengisi (sealing material).

3. Injeksi Retak

Proses injeksi hampir sama dengan proses merekatkan sambungan. Apabila penyebab kerusakan diketahui, sangat efektif bila menghilangkan penyebab kerusakan dalam waktu yang sama, seperti merekatkan sambungan. Retakretak yang tidak berkembang, patahan, ketidakrataan longitudinal, pelepasan butir mengelupas, lubang, retak buaya, pecah-pecah, dan sebagainya.Dua jenis 
pengikat dipakai untuk menambal yaitu aspal dan semen. Kombinasi yang akan digunakan, ditentukan dengan cermat oleh tingkat kekerasan, keadaan lalulintas, keadaan mendesak, ekonomis, dan lain-lain.

4. Penambalan dengan Bahan Semen

Bahan semen adalah yang paling sering dipilih untuk perbaikan slab beton karena campuran ini dapat memenuhi hasil yang diharapkan,akan tetapi mempunyai kerugian yaitu sulitnya dalam proses curing. Dengan mempertimbangkan kondisi lalu-lintas, semen yang paling cocok dipilih dari mulai semen biasa,semen dengan kekuatan awal yang tinggi, semen dengan kekuatan awal yang super tinggi. Dalam hal dimana lapisan tipis yang akan diterapkan, apabila ketebalan lapisan agak besar, digunakan beton dengan ukuran agregat kasar lebih kecil dari sepertiga tebalnya. Dalam mencampur mortar dan semen, harus diperhatikan agar kadar semen tidak terlalu berlebihan dari yang diperlukan. Suatu bahan tambah dapat di gunakan dalam pencampuran untuk mencegah masuknya udara guna mengurangi air, untuk mempercepat atau memperlambat pengerasan beton, sesuai keperluan.

5. Pelaksananan Penambalan

a. Pelaksanaan penambalan dilaksanakan sebagai berikut: buang bagian yang rusak dari slab, hancurkan konstruksi sambungan dengan pahat dan jaga agar keadaannya basah, serta bersihkan bubuk beton. Dalam pelaksanaan penghancuran, kalau terjadi pemotongan tulangan beton dan tulangan susut harus dapat tersambung kembali.

b. Tebarkan adukan semen selagi permukaan yang ditambal masih dalam keadaan jenuh air - keadaan kering.

c. Sebelum adukan semen, bentuk dan tempatkan campuran semen yang sudah siap atau adukan, tanpa menambah air lagi.

d. Padatkan dan gelarkan semen atau adukan serta ratakan dengan alat pengaci.

e. Sesudah 30 - 60 menit kemudian, padatkan lagi adukan beton dan ratakan sampai pada ketinggian yang diinginkan. Peraturan mengenai leveling seharusnya digunakan dalam pekerjaan finishing demi menjamin kerataan. Tekstur permukaan harus dibuat sedemikian rupa sehingga sama dengan tektur permukaan di sekitarnya.

f. Perawatan (curing) basah di laksanakan dengan menggunakan kain basah atau karung basah. Jangka waktu perawatan tergantung dari jenis semen.

6. Perbaikan Lapis Atas

Dalam metode ini, digunakan pelapisan tipis untuk mengatasi kerusakan permukaan seperti: retak-retak buaya, pelepasan butir (raveling), pelicinan (polishing), mengelupas (scaling), dan sebagainya.

7. Cara Injeksi

Dalam cara ini, rongga udara diantara slab beton dengan lapis pondasi diisi, atau posisi slab yang turun didorong ke atas ke posisi semula. Metode ini tidak mahal dan cukup efektif untuk memperpanjang umur jalan.

8. Cara Injeksi Semen

Ada dua cara/metode dalam hal injeksi dengan semen.Pertama mengisi rongga udara antara beton dengan lapis pondasi, yang kedua mengangkat slab beton yang turun.Cara injeksi dengan semen memerlukan waktu perawatan yang cukup lama dibandingkan dengan injeksi aspal, waktu perawatan kurang lebih memerlukan waktu 3 hari. Apabila waktu perawatan kurang, air pada material injeksi akan terpompa keluar dan ini akan menyebabkan kehancuran slab. Bahan injeksi umumnya semen dan air, biasanya ditambahkan tanah yang 
berbutir halus, pasir, dan gips. Biasanya ditambahkan juga semacam bubuk alumunium.

9. Cara pelaksanaan hampir sama dengan injeksi aspal.

a. Apabila digunakan cara mengangkat slab beton yang turun, buat lubanglubang.

b. Untuk penyemprotan lakukan seperti pada injeksi aspal.

c. Pompa grouting atau mud-jack dapat digunakan sebagai mesin/alat injeksi. Tekanan injeksi sebesar $3-5 \mathrm{~kg} / \mathrm{cm}$

d. Untuk mengangkat slab beton, injeksi dimulai pada lubang-lubang di daerah slab yang mengalamai penurunan paling besar.

e. Isikan semen mortar kedalam lubang injeksi. Dibuka untuk lalu lintas setelah 7 hari perawatan.

10. Perbaikan "Blow Up"

Apabila BlowUp terjadi, lakukan perbaikan sementara agar lalu-lintas tetap lancar. Kemudian ganti slab beton tersebut. Dalam hal sebagian terjadi BlowUp setempat, periksa sambungan dan lakukan perbaikan sementara karena mungkin ditempat lain hal ini terjadi. Apabila BlowUp relatif kecil, potong beton yang mencuat sejajar sambungan dengan jarak 50 - $60 \mathrm{~cm}$ dari sambungan dan hancurkan dengan alat penghancur guna meratakan bagian yang tadinya mencuat.Isikan tanah dan batu pecah sementara setelah beton tadi diangkat dan tutup dengan campuran aspal agar lalu-lintas tetap lancar. Setelah itu ganti dengan slab yang baru.

11. Perbaikan Pecah (Crushing)

Sementara hancurkan bagian yang pecah lalu tambal dengan campuran aspal.Setelah slab-slab cukup stabil, pasang expansionjoint dan ganti betonnya untuk penambalan dan penggantian slab.

\section{Grooving}

Grooving adalah membuat alur-alur kecil pada permukaan dengan gergaji intan atau tungsten carbide disc.Grooving ini mencegah hydroplaning dan meningkatkan tahan gesek antara roda dan permukaan jalan dengan mencegah adanya lapisan air antara permukaan jalan dan ban kendaraan.Grooving dilakukan secara melintang atau memanjang, tapi biasanya pada arah melintang.Grooving arah melintang sangat baik untuk keperluan drainase, dan untuk kelandaian yang cukup besar.

13. Perbaikan Slab Beton yang Rusak

Slab beton yang naik karena tanah di bawahnya ekspansif, perlu diganti setelah sebelumnya dilakukan usahausaha penanganan sementara untuk kelancaran lalu lintas. Pada dasarnya ada dua cara perbaikan yaitu:

1. Cara pelapisan (overlay).

2. Cara dengan penggantian.

Dalam hal diterapkan cara pelapisan, perbaikan yang dilakukan adalah kombinasi dari injeksi dan pengontrolan retak refleksi sesuai dengan tingkat kerusakan slab. Metoda yang akan digunakan harus ditentukan setelah dilakukan pemeriksaan secara teliti terhadap kondisi kerusakannya. Adapun cara perbaikan antara lain adalah:

\section{A. Metoda Pelapisan}

Dalam hal kerusakan berupa retakretak, kerusakan-kerusakan.permukaan atau karena keausan permukaan terlalu banyak (stripping) maka umur beton dapat diperpanjang dengan melakukan pelapisan, baik dengan campuran aspal maupun dengan beton.

Perencanaan Tebal Pelapisan

Penentuan tebal pelapisan ini sama dengan penentuan tebal perkerasan aspal pada umumnya. Tebal minimal pelapisan dengan campuran aspal adalah $4 \mathrm{~cm}$.

\section{Catatan :}

Apabila tebal pelapisan campuran aspal yang diperlukan lebih dari $10 \mathrm{~cm}$, disarankan mempergunakan campuran bergradasi terbuka,(masing-masing tebal $5 \mathrm{~cm}$ ) untuk mencegah retak refleksi. 
Pelaksanaan Pelapisan

Untuk pelaksanaan, hal-hal di bawah ini perlu diperhatikan:

a. Apabila pelapisan yang diperlukan cukup tebal, naikkan terlebih dahulu perlengkapan jalan lainnya seperti kereb, saluran tepi dan lain-lain.

b. Lakukan cara ini bersama-sama dengan metoda penggantian parsial atau dengan injeksi pada beton yang mengalami kerusakan cukup berat.

c. Isi sambungan-sambungan dan retakretak, kerusakan pelandaianpelandaian (taper) yang lebih dari 3 $\mathrm{cm}$, perbaiki pelepasan-pelepasan butir dengan kedalaman lebih dari $3 \mathrm{~cm}$, ketidakrataan memanjang dan kerusakan-kerusakan sudut.

d. Sebelum penyemprotan sapu slab-slab beton dan bersihkan kotoran-kotoran, lumpur dan lain-lain. Kalau mempergunakan aspal semprotkan setipis mungkin.

e. Perkerasan harus sama dengan lapis permukaan perkerasan aspal.

\section{B. Metoda Rekonstruksi}

Rekonstruksi dilakukan apabila cara pemeliharaan atau pelapisan tidak dapat dilaksanakan karena kerusakannya cukup berat. Dalam hal ini ada dua cara rekonstruksi, pertama dengan beton semen yang kedua dengan beton aspal. Pemilihan dilakukan dengan mempertimbangkan luas daerah yang akan diganti, kualitas tanah dasar, lapis pondasi (base) dan kondisi lalu-lintas.

\section{Perencanaan}

Tebal lapis pengganti perencanaan tebal perkerasan pengganti harus direncanakan sama seperti untuk perkerasan aspal beton atau semen beton. Dalam hal perbaikan sementara, tebal perkerasan pengganti harus sesuai dengan tebal perkerasan disebelahnya.

Pelaksanaan

Dalam pelaksanaan rekonstruksi perlu diperhatikan hal-hal sebagai berikut : a. Bongkar slab beton, ambil minimum satu unit slab.

b. Gali lapisan pondasi, dengan tidak merusak perkerasan di sebelahnya yang masih utuh/baik. Gunakan alat penggali secukupnya, kemudian selesaikan dengan tangan.

c. Padatkan setiap sudut lapisan pondasi dengan mesin penggilas. Gunakan alat pemadat kecil untuk pemadatan tepi sudut, dan tempat-tempat lainnya yang biasanya pemadatan dilakukan kurang sempurna.

d. Dalam hal jalan harus tetap dibuka untuk lalu-lintas selama pekerjaan dilakukan, perlu dibuat lapis permukaan sementara agar lalu-lintas tidak terganggu. Untuk ini dapat digunakan campuran aspal.

e. Dalam hal rekonstruksi dengan menggunakan perkerasan aspal, selesaikan dulu sampai lapis pengikat (binder course), padatkan dengan membuka lalu- lintas selama 1-2 minggu. Dalam hal ini pelandaian/transisi (taper) perlu dibuat guna menjamin keamanan dan keselamatan pemakai jalan.

f. Apabila penggantian menggunakan perkerasan semen, perlakuan terhadap sambungan konstruksi pada slab yang ada dilaksanakan sesuai dengan.

g. Jarak antara sambungan melintang ditentukan sama seperti perkerasan kaku yang baru. Apabila penggantian hanya dilakukan pada salah atu lajur, posisi dan konstruki sambungan harus sama dengan lajur sebelahnya. Untuk sambungan memanjang antara slab yang diganti dengan slab yang ada, dengan membuat lubang pada bidang permukaan beton yang ada atau menggunakan paku beton (rock bolts).

h. Sambungan antara bagian jalan lama dengan slab yang direkonstruksi diberi pengisi sambungan.

i. Beton untuk pengganti harus sama mutunya dengan beton pada perkerasan lama. Apabila ada kesulitan membawa peralatan 
pencampuran beton yang besar, sedangkan daerah yang diperbaiki relatif kecil dan lokasinya tersebar, agar dipergunakan campuran beton dengan konsistensi yang sesuai. Kalau dilakukan dengan tangan, gunakan campuran beton dengan slump 5-6 cm, dengan pertimbangan faktor pengangkutan.

Adapun macam-macam kerusakan antara lain adalah sebagai berikut:

\section{Memudarnya beton}

Kerusakan memudarnya beton yang terjadi sebesar $6 \mathrm{~m}^{2}$ atau $0,08 \%$ dari luas total kerusakan $\left(728 \mathrm{~m}^{2}\right)$. Kerusakan ini juga terjadi pada ruas jalan dan mempengaruhi kualitas jalan tersebut.Penyebab kerusakan ialah pelat beton terlalu tipis dan pengecoran beton buruk.Perbaikan dapat dilakukan penambalan diseluruh kedalaman pelat yang pecah.

\section{Retak memanjang}

Kerusakan memudarnya beton yang terjadi sebesar $6 \mathrm{~m}^{2}$ atau $0,08 \%$ dari luas total kerusakan $\left(728 \mathrm{~m}^{2}\right)$. Kerusakan ini juga terjadi pada ruas jalan dan mempengaruhi kualitas jalan tersebut.Penyebab kerusakan ialah pelat beton terlalu tipis dan pengecoran beton buruk.Perbaikan dapat dilakukan penambalan diseluruh kedalaman pelat yang pecah.

\section{Amblas}

Kerusakan amblas yang terjadi sebesar 7 $\mathrm{m}^{2}$ atau 0,093\% dari luas total kerusakan $\left(728 \mathrm{~m}^{2}\right)$.Kerusakan ini sangat mengganggu kelancaran lalu lintas.Perbaikan untuk beda elevasi kurang dari $25 \mathrm{~mm}$ dapat diberikan lapisan perata dan pengisi retakan, dan jika beda elevasi lebih dari $25 \mathrm{~mm}$ maka perbaikan dilakukan dengan penambalan lapisan aspal (overlay).

\section{Retak Melintang}

Kerusakan retak melintang yang terjadi sebesar $15 \mathrm{~m}^{2}$ atau $0,2 \%$ dari luas total kerusakan $\left(728 \mathrm{~m}^{2}\right)$.Kerusakan mempengaruhi kualitas jalan tersebut. Perbaikan untuk celah kecil kurang dari $5 \mathrm{~mm}$ dapat dilakukan dengan pengisian celah,sedangkan untuk celah lebih dari $5 \mathrm{~mm}$ dilakukan pembangunan kembali pelat secara lokal dan penambalan di seluruh kedalaman.

\section{KESIMPULAN}

Dari uraian yang telah disajikan dalam laporan penelitian ini, maka dapat ditarik kesimpulan bahwa penyebab dari kerusakan jalan Desa Badurame-Geger adalah tidak adanya tulangan pada plat, karena keretakan memanjang yang paling dominan dan berkurangnya mutu beton akibat kurangnya pengawasan. Nilai kerusakan pada jalan Badurame-Geger adalah pada keretakan yang memanjang mencapai 9,33\%, memudarnya beton $0,08 \%$, amblas 0,093 dan retak melintang $0,2 \%$. Solusi untuk mengatasi kerusakan pada jalan Desa Badurame-Geger dengan menggunakan metode/acuan dari bina marga yaitu penambalan, pelapisan ulang, pengisian, rekonstruksi lokal, dan overlay.

\section{REFERENSI}

Arthur Wignal,Peter S.Kendrick,Roy Ancil,Malcolm Copson .2003.Proyek Jalan,Teori Dan Praktek. Jakarta :Erlangga

Bina Marga Tata Cara Perencanaan Geometrik Jalan Antar Kota, (TPGJAK) No. 038/T/BM/1997. Ketentuan Klasifikasi Jalan.

Direktorat jendral Bina Marga, (1991), Tata Cara Pemeliharaan Perkerasan Kaku (Rigid Pavement).

Direktorat Jendral Bina Marga, (1990), Panduan Penentuan Klasifikasi Fungsi Jalan Di Wilayah Perkotaan

Hendarsin, Shirley. 2000.Perencanan Teknik Jalan Raya.Bandung: Politeknik Negeri Bandung

Kementrian Pekerjaan Umum Direkturat Bina Marga 2012. Manual desain perkerasan jalan 